\title{
Purse-seine vessels as platforms for monitoring the population status of dolphin species in the eastern tropical Pacific Ocean
}

\author{
Cleridy E. Lennert-Cody ${ }^{1 *}$, Mark N. Maunder ${ }^{1}$, Paul C. Fiedler ${ }^{2}$, Mihoko Minami ${ }^{3}$, Tim Ger- \\ rodette $^{2}$, Jeremy Rusin ${ }^{2}$, Carolina V. Minte-Vera ${ }^{1}$, Michael Scott ${ }^{1}$, Stephen T. Buckland ${ }^{4}$
}

\begin{abstract}
In the eastern tropical Pacific Ocean, yellowfin tuna (Thunnus albacares) are often found in association with spotted (Stenella attenuata) and spinner (S. longirostris) dolphins. Purse-seine vessels use this co-occurrence to locate the tuna by searching for dolphins and associated birds. Data collected by onboard observers since the late 1970s were used to develop indices of relative abundance for dolphins, based on line-transect methodology, when the primary method of detection of dolphin herds was with binoculars. However, trend estimation was subsequently discontinued in 2000 due to concerns about changes in reporting rates of dolphin herd detections with increased use of helicopter and radar search. At present, as a result of a hiatus in fisheryindependent surveys since 2006, fisheries observer data are the only source of information with which to monitor the status of eastern tropical Pacific Ocean dolphin populations. In this paper, trend estimation with the onboard observer data is revisited using a sightings-per-unit-effort approach. Despite different assumptions and model structure, the results indicate a lack of independence between the distribution of search effort and the search methods used, and the abundance of dolphin herds associated with tunas, on several spatial and temporal scales. This lack of independence poses a considerable challenge to the development of a reliable index of relative abundance for dolphins with these data. Given these results, alternatives for dolphin abundance estimation are discussed. One alternative is the use of purse-seine vessels for line-transect surveys during fishery closure periods. Another alternative is the use of purse-seine vessels during normal fishing operations as platforms for the collection of mark-recapture data (e.g., passive integrated transponder tags or genetics sampling). Life-history data collection, as a supplement to the collection of other data types, is also discussed. Further research and development is needed to assess whether these alternative methods will be useful.

${ }^{1}$ Inter-American Tropical Tuna Commission, 8901 La Jolla Shores Drive, La Jolla, California USA 92037

2 Marine Mammal and Turtle Division, Southwest Fisheries Science Center, National Marine Fisheries Service, NOAA, 8901 La Jolla Shores Drive, La Jolla, California USA 92037

${ }^{3}$ Department of Mathematics, Keio University, 3-14-1 Hiyoshi, Kohoku-ku, Yokohama, Kanagawa 223-8522, Japan

${ }^{4}$ Center for Research into Ecological and Environmental Modelling, The Observatory, Buchanan Gardens, University of St Andrews, St Andrews, Fife KY16 9LZ, Scotland, UK

*Corresponding author: clennert@iattc.org
\end{abstract}

Keywords: dolphin abundance, line-transect, CPUE, bycatch, generalized additive model

\section{Introduction}

Mortality of dolphins in the eastern tropical Pacific Ocean (ETP) purse-seine tuna fishery is an iconic conservation issue. In the ETP, yellowfin tuna (Thunnus albacares) are often found in association with spotted (Stenella attenuata) and spinner (S. longirostris) dolphins (NRC, 1992). 
Since at least the 1960s, purse-seine vessels have used this co-occurrence to locate the tuna by searching for dolphins, and associated birds, with high-power binoculars, and more recently, high-resolution radar and helicopters (NRC, 1992; Lennert-Cody et al., 2001). Historically, this fishing method resulted in significant bycatch of dolphins, which has since been greatly reduced through fishermen's ingenuity and implementation of management measures (MMPA, 1972; Lo and Smith, 1986; NRC, 1992; Joseph, 1994; Wade, 1995; Hall, 1998; IATTC, 2013).

Population dynamics modeling of dolphins in the ETP has historically been one of the primary means of evaluating the efficacy of bycatch reduction measures for these species (Gerrodette and Forcada, 2005; Reilly et al., 2005; IATTC, 2006; Wade et al., 2007, Gerrodette et al., 2008). Dolphin population assessments require an index of either relative or absolute abundance from which inferences are made about trends in population size through time. Indices of dolphin abundance have been developed from both fishery-dependent and fishery-independent data. In the case of fishery-dependent data, information on dolphin herd sightings is available because fishermen in the ETP use the presence of dolphins, as well as birds and splashes, to locate tunas (NRC, 1992). In the early years of the fishery, fishermen would search for these cues primarily using high-powered binoculars. Observers aboard the tuna vessels recorded information about the dolphin herd encounters and position information for the purse-seine vessel. Indices of relative abundance were developed from these data in the 1980s based on line-transect methodology (Buckland and Anganuzzi, 1988; Anganuzzi and Buckland, 1989; Buckland et al., 1992). However, trend estimation was discontinued in 2000 due to concerns about changes in reporting rates of dolphin herd detections with the increased use of helicopter and radar, in addition to binoculars, to search for dolphins and tunas (Lennert-Cody et al., 2001). Additional concerns have been raised about potential issues associated with herd size estimation (Ward, 2005). Between 1979 and 2006, the US National Marine Fisheries Service (NMFS) conducted periodic fishery-independent surveys in the ETP for the purpose of estimating dolphin absolute abundance (Gerrodette et al., 2008, and references therein). While such surveys can have the advantage of avoiding time-varying biases due to changes in fishing behavior, they are costly and, as a result, obtaining adequate coverage and precision for monitoring widely distributed marine species is difficult.

One of the advantages of data collection by observers during normal fishing operations onboard tuna purse-seine vessels is that large amounts of data are obtained, with generally good spatial and temporal coverage. However, fishery-dependent data come with the potential for biases when used to develop indices of relative abundance (Maunder et al., 2006). At present, as a result of a hiatus in fishery-independent surveys since 2006, purse-seine observer data are the only source of information with which to monitor ETP dolphin population status. In the first part of this paper, the challenge of estimating dolphin trends with the purse-seine observer data for the offshore spotted dolphin is revisited and the reliability of estimates computed from these data are discussed. To address problems related to sighting data quality and biases caused by changes in the use of different search methods through time (Lennert-Cody et al., 2001), a catch-per-uniteffort-type approach to trend estimation was adopted based on generalized additive models. This methodology for trend estimation does not require sighting bearing and distance information, and can be used to control for covariate affects, such as changes in searching behavior. In the second part of this paper, other options for obtaining dolphin abundance indices from different data types that may be collected aboard purse-seine vessels are discussed. Issues associated with herd 
size estimation, such as those raised by Ward (2005) and Buckland and Anganuzzi (1988), are not addressed.

\section{Trends from fishery-dependent data}

\subsection{Data}

During the course of daily fishing operations, observers of the Inter-American Tropical Tuna Commission (IATTC) aboard large ${ }^{1}$ purse-seine vessels recorded data on vessel activities (e.g., running, searching, drifting, setting), fishing operations, and dolphin sightings. These data were used to obtain estimates of distance travelled while searching, species and number of dolphins in each dolphin herd sighted, and information on other factors that may affect dolphin herd sighting rates and herd size (e.g., fishing location and season).

Purse-seine vessel searching behavior is complex and not all details of searching activities were recorded by onboard observers. Large purse-seine vessels that fish for tunas associated with dolphins use three methods to search for the dolphins and tunas: binoculars (typically $25 \mathrm{X}$ mounted binoculars, from one or several locations on the vessel), radar, and helicopter. The radar is operated by the crew from the bridge of the vessel. The helicopter is piloted by a special crew member, and due to space constraints and safety concerns, observers are not allowed in the helicopter. Unfortunately, observers did not record which search methods were in use during each searching event, and thus, it is not possible to assign periods of search to particular search methods. Moreover, the helicopter may have searched well away from the purse-seine vessel and its position information was not available to the observer. Therefore, it is only possible to compute a rough measure of searching effort from time and position data for the purse-seine vessel itself.

Observers recorded all dolphin sightings of which they were aware. An initial estimate of dolphin herd size and species composition was recorded by the observer as soon as he became aware of the sighting. This may have been a crew member's initial estimate, or the observer's own initial estimate, if he was able to see the dolphins. A dolphin herd sighting may have begun with the visual cue of the mammal themselves or it may have begun with other cues, such as splashes or birds associated with the dolphins. The association of birds with dolphins enables sightings to be made at much greater distances from the vessel because birds can be visible over the horizon. If the dolphin herd was later involved in a purse-seine set, the observer would have continued to revise his estimate of herd size and species composition, producing a "best" estimate. This best estimate is the observer's estimate of the size of the entire herd, and includes an estimate of the number of dolphins that were in the original herd but evaded encirclement with the purse-seine net or were intentionally cut-out of the encircled portion of the herd (NRC, 1992; Lennert-Cody and Scott, 2005). With possible exception of evasion, a dolphin herd sighting leading to a purse-seine set is similar to a survey vessel entering 'closing mode' in a fishery-independent line-transect survey (e.g., Strindberg and Buckland, 2004). Additional information recorded for each sighting includes the distance and bearing to the sighting from the vessel.

\footnotetext{
${ }^{1}$ Defined as those with carrying capacities greater than 363 metric tons (IATTC Class 6), all of which are required to carry observers.
} 
For this analysis, to try to standardize searching practices among vessels and trips through time, data were limited by the following criteria:

1. To ensure homogeneity of searching techniques, data collected prior to 1990 were excluded, because information on radar use did not become available until the late 1980s (LennertCody et al., 2001).

2. To ensure that vessel crew were actively searching for dolphins, and that the vessel was not switching fishing modes, depending on availability of tunas as free schools or as schools associated with dolphins, trips making fewer than $50 \%$ of their sets on tunas associated with dolphins were excluded (but see Section 2.5).

3. Days when the vessel was not actively searching with the observer on duty, days without at least two valid positions, days where the vessel was at or near full fish-carrying capacity ( $\geq$ 90\% capacity; to remove periods of lower-intensity search), and days with rough sea state (Beaufort > 4) (to exclude periods when detection might be impeded by weather) were excluded.

4. If one or more sets were made during a day, any recorded search and sightings between the sighting that led to a set and the set itself were excluded to remove periods of lower-intensity search.

5. To minimize the effects of the sundown prohibition (AIDCP Annex VIII page 22 3(e) http://iattc.org/PDFFiles2/AIDCP-amended-Jul-2014.pdf ) which took effect in 1993 and which may result in lower-intensity search at the end of the day, search and sightings made after 17:00 h were excluded.

Further restrictions were applied to the dolphin sightings data. Sightings recorded as detected by "other" methods (most likely made by the observer) were excluded, as were sightings with incomplete information (missing herd size, missing or unknown species composition). For the most part, sightings with incomplete information were made by the helicopter too far from the vessel for any information on herd characteristics to be obtained. Sightings behind the vessel (bearings between $90^{\circ}-270^{\circ}$ ) were also excluded; it was assumed that all searching effort took place in the direction of travel of the vessel. Sightings of herds that did not include offshore spotted dolphins were excluded.

\subsection{Search effort}

Search effort was computed in kilometers. A vessel was considered to be searching if the vessel was in active search mode (i.e., not running, drifting, chasing or setting) and the observer was on duty. All events recorded by the observer during these active, on-duty search periods for each trip-day were processed to define searching 'segments.' A search segment was defined as any consecutive pair of events recorded by the observer. Search segment start and end positions were estimated if no positions were available. Positions were estimated from known positions as close in time as possible to the segment without position information. Search segments were mostly short in duration; about $70 \%$ were of less than one hour, and about $99 \%$ were of less than 2 hours. Search effort was stratified by $1^{\circ}$ areas; if a search segment crossed a $1^{\circ}$ area boundary, effort was distributed between the $1^{\circ}$ areas, assuming a linear path between the segment start and end positions. Because of the way search segments were defined, sightings were always associated with segment end positions. It is assumed that on such small spatial scales, search 
effort was randomly distributed with respect to dolphin abundance. The spatial distribution of search effort is shown in Figure 1, and is generally similar to the spatial distribution of sets on tunas associated with dolphins within the ETP (e.g., Watters, 1999).

\subsection{Search behavior}

The three different search methods do not appear to have operated independently. As inferred from the distance to sightings from the purse-seine vessel (Figure 2), the three search methods operated at overlapping distances, with helicopters operating the furthest from the vessel. Sightings by all three methods were made close to the vessel, which is consistent with the reported use of helicopters to investigate binocular and radar sightings for the presence of tuna. The overlap in sighting distances means that sightings reported by binocular search could have been detected by the helicopter and/or on radar further from the vessel, but not reported, although the potential evasive response of dolphins (e.g., Pryor and Norris, 1978; Lennert-Cody and Scott, 2005) means this would not be guaranteed. The observer recorded the search method that he believed to have first sighted the dolphin herd; no data were collected by the observer as to when (or if) the same herd is seen by other search methods. To avoid confusion, hereafter the search method recorded by the observer will be referred to as the 'detection type' because search method-specific estimates of effort are not available.

Although the search effort associated with each of binoculars, radar, and helicopter, is unknown (as explained above), changes in the sighting reporting rates by the three detection types suggest that searching techniques evolved over the 1990-2013 period. The percentage of sightings by detection type changed from mostly binocular sightings to mostly radar and helicopter sightings (Figure 3a). Helicopters had the highest percentage of sightings that led to purse-seine sets and binoculars the lowest (Figure 3b). Differences in percentages of radar and helicopter sightings that resulted in sets, as compared to the percentage of binoculars sightings that resulted in sets, are believed to be indicative of an underreporting of sighting information associated with helicopter and radar (Lennert-Cody et al., 2001). In particular, it is believed that helicopter crew only reported dolphin sightings to the vessel that were worth considering for a set.

To capture any trend in changes in searching practices and sighting data availability through time by helicopter and radar, relative to binoculars, a trip-specific detection variable, $r$, was defined. For the $j^{\text {th }}$ trip, $r_{j}$ was defined as the proportion of sightings by helicopter and radar in trip $j$ (equal to the sum of sightings reported by either helicopter or radar in the $j^{\text {th }}$ trip, divided by the total number of sightings for the $j^{\text {th }}$ trip). If the proportion of sightings by detection type is positively correlated with search method-specific effort, then values of $r$ near 0 would imply low helicopter/radar effort, while values of $r$ near 1 would imply high helicopter/radar effort. An important aspect of $r$ that may allow for identification of the effects of changes in searching behavior through time from other temporal trends, such as trends in dolphin abundance, is that much of the range of values spanned by $r$ can be found in most years (Figure 4). The annual median values of $r$ increase through time as would be expected given the temporal trends in sightings by detection type (Figure 3 ).

\subsection{Trends model}

In contrast to previous analyses where a line-transect approach for trend estimation was used (Buckland and Anganuzzi, 1988; Anganuzzi and Buckland, 1989; Buckland et al., 1992; 
Lennert-Cody et al., 2001), a catch-per-unit-effort (CPUE) approach to trend estimation was taken in this analysis, in part because of concerns about the quality of the bearing data (LennertCody et al., 2001) and the potential effects that could have on estimated abundance (Barlow, 2015). The index of relative abundance was based on the number of dolphins per kilometer searching per trip-day- $1^{\circ}$ area. A trip-day was the minimum time unit for the analysis because searching was a day-time activity, and it was not possible to unequivocally associate periods of search with individual sightings within a trip-day. This analysis used all offshore spotted dolphin sightings out to $20 \mathrm{~nm}$ from the vessel for which there was an observer's estimate of herd size and species composition (initial or best) (2.4\% of sightings were excluded with the $20 \mathrm{~nm}$ restriction). The 20-nm restriction had the greatest effect on helicopter sightings (Figure 2); almost all binocular sightings and most radar sightings were made within $20 \mathrm{~nm}$ of the vessel. Therefore, the analysis included all the dolphin herds that might have been recorded as binocular sightings, if they had not been recorded as sightings by the other search methods. A total of 362,180 trip-day- $1^{\circ}$ area "observations" and 99,598 dolphin sightings were used in the analysis, representing 3,888 trips of 153 vessels. Most trip-day $-1^{\circ}$ areas had no herd sightings (78\%), 18\% had one herd sighting, with a maximum of 6 herd sightings per observation. Crew-only sightings were excluded because vessel crew usually did not distinguish between the offshore spotted dolphin and the coastal spotted dolphin, and because crew estimates of group size have been shown to differ from those made by observers (Buckland and Anganuzzi, 1988). However, it is noted that a preliminary analysis of encounter rate that also included crew-only sightings produced very similar results, most likely because crew-only sightings amounted to only a $7 \%$ increase in the number of sightings.

Herd size estimates were used "as is" in this analysis without any adjustments. The observer's best estimate of offshore spotted dolphin herd size was used, if available; otherwise, the observer's initial estimate was used. Herd size estimates ranged from 1 to 9,999 dolphins with a median value of 412 dolphins (inter-quartile range: 218-700). An estimate of 9,999 indicates that there were at least that many animals; there were only two observations with a herd size of 9,999 in the data set used in this analysis. For sightings with both an observer's best and an observer's initial estimate of the number of offshore spotted dolphins, the Spearman rank correlation between the two estimates was 0.96 for pure herds of spotted dolphins and 0.90 for mixedspecies herds ${ }^{2}$. Therefore, in this analysis, the initial estimates of herd size were not adjusted (c.f. Buckland and Anganuzzi, 1988). Set-sightings, those sightings that led to a set, and for which an observer's best estimate of herd size was available, accounted for $83.3 \%$ of the sightings used in this analysis.

It was assumed that the number of dolphins seen while searching arises from a two-stage process: encountering dolphin herds and dolphin herd size. In addition, for the formulation of the CPUE-type model, it was assumed that, having accounted for covariate effects (described below), the spatial distribution of search effort, and the search methods being used, were independent of dolphin abundance and density of dolphin herds associated with tunas.

For $N=$ number of herds encountered, $W=$ herd size, and $N \sim F_{N}(n)$ and $W_{i} \sim F_{W}(w), i=1,2, \ldots$

\footnotetext{
${ }^{2}$ The estimated slopes of the regression lines were $0.952($ s.e. $=0.0014)$ and 0.920 (s.e. $\left.=0.0022\right)$, respectively.
} 
(where $W_{i}$ is only observable if $i \leq N$ ), the number dolphins encountered, Y, was defined as

$$
Y= \begin{cases}\sum_{i=1}^{N} W_{i} & \text { if } N>0 \\ 0 & \text { if } N=0\end{cases}
$$

Assuming the summation above is zero if $N$ is zero, the mean of $Y$ is given by (Wald, 1944)

$\mathrm{E}(\mathrm{Y})=E(E(Y \mid N))=E\left(E\left(\sum_{i=1}^{N} W_{i} \mid N\right)\right)=E(N E(W))=E(N) E(W)$

$E(N)$ and $E(W)$ were modeled separately, and from these components a standardized trend was computed. The approach taken to select covariates to model encounter rate and herd size was to include those covariates believed to be important based on our understanding of the fishing process. A statistically-based model selection procedure was not implemented because, in our experience, with this much data and a high percentage of zero-valued observations, many covariates may be statistically significant even if they are not sensible from a process point of view.

A zero-inflated Poisson (ZIP; e.g., Minami et al., 2007; Zuur et al., 2009) generalized additive model (GAM; Wood, 2006) was used to model $N$ as a function of covariates. A ZIP distribution is a mixture distribution that can be used to model data with an excess of zero-valued observations. In a ZIP distribution, zeros can arise from either the binomial process or the Poisson count process. A ZIP model was selected here because of the possibility that the data were zero-inflated due to under-reporting of sightings, and because preliminary analyses with a Poisson model did not adequately capture the non-zero counts. The same covariates were used in each part of the ZIP regression model:

$\log \left(\frac{p_{i}}{1-p_{i}}\right)=$ year $+c($ month $)+f\left(1^{\circ}\right.$ latitude, $1^{\circ}$ longitude $)+f(k m$ search $)+f(r)$

$\log \left(\mu_{i}\right)=$ year $+c($ month $)+f\left(1^{\circ}\right.$ latitude, $1^{\circ}$ longitude $)+f(k m$ search $)+f(r)$

where $p_{i}$ is the probability that the $i^{\text {th }}$ observation was in the zero state, $\mu_{i}$ is the mean of the $i^{\text {th }}$ observation for the count (Poisson) state, year is categorical (a factor), $c$ represents a cyclic cubic spline smooth, and $f$ indicates a smooth term or surface based on thin plate regression splines (subscripts on the right-hand side of the equations are supressed for simplicity). Based on the assumption that the smooth terms for $\mathrm{km}$ search (kilometers searching) and $r$ should be monotonic, the number of basis functions for these two terms was set to 4. The ZIP GAM was fitted by an EM algorithm (e.g., Dempster et al., 1977; Minami et al., 2007) and the $m g c v$ library (Wood, 2006) in R (R Development Core Team, 2012). The EM algorithm was run for 600 
iterations, with the smoothing parameters fixed at the values obtained at the $20{ }^{\text {th }}$ iteration. A zero-inflated negative binomial (ZINB) was not fitted to these data because preliminary analyses indicated that the added variance component in the ZINB (e.g., Minami et al., 2007) would be very small and the trade-off in terms of model complexity was not warranted.

The rationale behind the covariates included in the ZIP model for encounter rate was as follows. The predictors latitude, longitude and month were included in the model because fishery activity varies both spatially and seasonally (e.g., IATTC, 2013; Hall et al., 1999; Watters, 1999), and the response of dolphins to tuna vessels has been shown to have a spatial component (LennertCody and Scott, 2005). Effort was included because it was expected that the encounter rate should be a monotonically increasing function of the distance covered while in search mode. In this analysis it was assumed that herd size does not affect detection in the typical sense. Lack of reporting, as opposed to lack of detection, was believed to be a greater problem, and for this reason a zero-inflated model was used (assuming some percentage of herd detections go unreported) and the covariate $r$ was included as a predictor. Future analyses might instead attempt to model individual herd sightings and consider herd size as a covariate, as well as other herd-specific factors and factors describing sighting conditions, such as Beaufort sea state. However, separating reporting effects from detection effects may not be possible with these data because of a correlation of dolphin herd size with tuna catch (Hall et al., 1999) could lead to a confounding of the two effects. Instead of including a random effect for vessel in the model, the data used in the analysis were limited to trips with more similar searching practices (see Section 2.1).

Because herd size was a count, and strongly right-skewed, a negative binomial (NB) GAM was used to model $W$ as a function of covariates:

$$
\begin{gathered}
\log \left(v_{k}\right)=\text { year }+c(\text { month })+f\left(1^{\circ} \text { latitude, } 1^{\circ} \text { longitude }\right)+\text { set sighting } * \text { detection type } \\
+ \text { mixed species }
\end{gathered}
$$

where $v_{k}$ was the mean number of offshore spotted dolphins in the $k^{\text {th }}$ herd, set sighting was a two-level factor indicating whether the sighting led to a set, mixed species was a two-level factor indicating whether the herd was pure offshore spotted dolphins or a mix of species, detection type was a three-level factor (levels: binoculars, helicopter, radar), and “*” denoted main effects and the first-order interaction (subscripts on the right-hand side of the equation are supressed for simplicity). The model was fitted with the $m g c v$ library in R. A negative binomial likelihood was used here even though $W$ cannot take the value 0 because although there are 0 -truncated NB GAM options in R (e.g., the library VGAM, Yee, 2014), that we are aware, these options do not offer two-dimensional smooth surfaces, and it was believe the two-dimensional spatial effects on the mean structure were important to capture. It is not expected that using the full NB likelihood versus a 0 -truncated NB likelihood would have much effect on the estimated mean structure because the overall distribution of herd size was distributed well away from zero; $90 \%$ of the observations were between $65-1500$ animals, and less than $0.1 \%$ of the observations were less than 5 animals.

The rationale behind the covariates included in the NB model for herd size was as follows. The predictors latitude, longitude and month were included in the model for the same reasons as 
noted above for the ZIP. The predictors set sighting and detection type were included in the model because herd size was found to vary depending on the detection type of the sighting and whether the sighting led to a set (Figure 5). Overall, dolphin herd size and tuna catch have been shown to be positively correlated (Hall et al., 1999), and thus, it would be expected that dolphin herds that were not set upon, i.e., were not associated with tuna or were not associated with enough tuna to be worth the vessel making a set ('non-set-sightings') were smaller herds. One possible reason herds reported by helicopters may have been larger than those reported by radar and binoculars is that helicopter sightings were more often associated with enough tuna to warrrant a set (Figure 3b). A factor for herds of mixed species was included because it was assumed that mixed-species herds could have a different mean number of offshore spotted dolphins; in general, mixed species herds have been shown to be larger than pure herds of offshore spotted dolphins (Hall et al., 1999).

To control for covariate effects on the estimated trend (e.g., Maunder and Punt, 2004), an index of relative abundance was computed by predicting the mean number of dolphins, based on the fitted ZIP and NB GAMs, on the same fixed spatial grid for each year, at fixed values of the other covariates. Covariates other than year, latitude, and longitude were fixed at the median for continuous variables, and at the most common value for categorical variables. All median/common covariate values were represented in all years. The fixed spatial grid was the collection of $1^{\circ}$ areas with any search effort in any of the 24 years. In each year, for each $1^{\circ}$ area, the estimated CPUE was the product of the estimated encounter rate and the estimated group size:

$[(1-\hat{p}) \cdot \hat{\mu}] \cdot \hat{v}$

The index for a given year was the sum of these $1^{\circ}$ area estimates.

\subsection{Standardized trend}

In spite of some shortcomings in terms of model fit, the results of this analysis have provided useful insights into the structure of the dolphin data that will be important to address before better trend models could be developed. With exception of the $\mathrm{km}$ search term in the logistic component of the ZIP regression model, all model terms for both components of the ZIP, and for the NB model, were significant (term-specific $p$-values < 0.01 ). However, model diagnostics suggested that there is room for model improvement. The ZIP regression model for encounter rate performed better $\left(\mathrm{AIC}^{3}=449,118\right)$ than a Poisson regression model ( $\left.\mathrm{AIC}=456,808\right)$, but still did not adequately fit the data. The percent deviance explained by the logistic component of the ZIP resgression model was $91 \%$, but the percent deviance explained by the loglinear (Poisson) component was only $7 \%$. The percent deviance explained by the NB regression model for herd size was $23 \%$. In addition, convergence of the EM algorithm for the ZIP was slow; at 600 iterations, the maximum difference in the latent variable was 0.015. Extensions to the EM algorithm (e.g., McLachlan and Krishnan, 2008) would need to be considered in the future to achieve better convergence. Future models also might include asymmetric smoothing for 2-D terms (i.e., the latitude-longitude surface), although in a preliminary analysis, a ZIP with a tensor

\footnotetext{
${ }^{3}$ For the ZIP, the AIC statistic (e.g., Burnham and Anderson, 2002) was defined as: $-2 * \log$ likelihood + $2 * \operatorname{sum}($ trace (influence matrices)).
} 
product basis (Wood, 2006) for the 2-D spatial term produced unstable results for the Poisson component. Despite this, the current model results provide information on the extent to which that data violate the primary assumptions about independence of effort and the abundance of dolphin herds associated with tunas, on a range of spatial and temporal scales, and illustrate that the processes behind the trends in the percentage of sightings by detection method (Figure 3 ) are likely more complex than had been assumed. Three points are described below in detail.

First, on the scale of a trip-day- $1^{\circ}$ area, the maximum amount of search effort that took place appears to have depended on whether any sets were made (i.e., on fishing success), producing a non-monotonic relationship between encounter rate and effort. The shape of the smooth term for $\mathrm{km}$ search estimated from the loglinear (Poisson) component of the ZIP regression model at distances less than about $120 \mathrm{~km}$ (the range over which confidence intervals are very small) (Figure 6a) illustrates this point; the smooth term for $\mathrm{km}$ search from the logistic component of the ZIP regression model was flat and not significant $(p$-value $=0.61)$. The shape of the smooth term from the loglinear part shows an initial increase with increasing effort up to about $50 \mathrm{~km}$, which would have contributed to an increase in the estimated mean number of sightings over that distance. This increase is followed by a decrease out to roughly $120 \mathrm{~km}$. It is hypothesized that this shape is consistent with a decrease in time available for searching on days when one or more sets were made, and thus, a decrease in the maximum distance that could have been covered in search mode on days when sets were made. Making a set is a time-consuming process; in 2013, the median time spent by a vessel from the start of the chase to the end of the set was 3 hours. To further explore this hypothesis, the quantiles of $\mathrm{km}$ search were comuted as a function of the number of set-sightings that occurred during the day (Figure 6b). The full range of search distances were associated with trip-day- $1^{\circ}$ areas with no set-sightings. However, the range of search distances shrinks, particularly the extent to which larger distances occurred, as the number of set-sightings increases, consistent with the hypothesis. It is noted that the data selection criterion (4) of Section 2.1 also would have contributed to reduced effort on days when sets were made (about $11 \%$ of effort was eliminated with this restriction). Although a day is a natural unit for the encounter rate data because search cannot take place at night, the data could be further aggregated in time and space. However, it is not clear what temporal and spatial scales should be selected, given the other processes occurring at larger spatial-temporal scales (see below).

Second, the types of search methods used at different times during a trip appear to have depended on the vessel's perception of the local abundance of dolphins associated with tunas or the local abundance of dolphins. The shape of the smooth term for the detection variable, $r$, from the logistic component of the ZIP regression model illustrates this point; the smooth term for $r$ in the loglinear (Poisson) component of the ZIP regression model was fairly flat (Figure 7). A monotonically increasing trend for $r$ from the logistic component was expected because it had been assumed that the proportion of sightings by detection type for a trip reflects the proportion of search method-specific effort, and that sightings would be more likely to be reported during search dominated by use of binoculars. (A monotonically increasing trend for $r$ would have indicated an increasing probability of being in the zero state with an increasing proportion of helicopter and radar sightings.) However, this would only be true if the search methods used were independent of abundance. The estimated smooth term for $r$ shows exactly the opposite trend than expected at small values of $r$, i.e., at high proportions of binocular sightings (Figure 7a). It is hypothesized that this pattern reflects use of different search strategies within a trip, 
depending on perceived abundance. 'Transit' and 'area' search are two examples of different types of searching strategies that could have taken place during a trip. The term transit search refers to search that occurred while in transit to a predetermined fishing area, and is characterized by mostly linear movement (at the resolution of our data) through a larger area, while the term area search refers to search that occurred within a predetermined fishing area, and is characterized by multiple passes of the vessel through a relatively small region (Figure 8). Helicopters may not have been as likely to be used during transit search because of the preception that encountering dolphins with tunas, or encountering dolphins, was less likely. Within a trip, therefore, an increase in binocular sightings, relative to helicopter sightings, could have occurred simply because the vessel was transiting through an area of low density of dolphin herds associated with tunas and/or an area of low dolphin abundance. Disentangling within-trip searching strategies, and quantifing their relative importance, will be difficult and subjective because different search strategies would have to be inferred from features such as search path characteristics. In order to better address this issue in the future, it would be important that, for at least a subset of vessel trips, helicopter position information were available for analysis, detailed helicopter activities were recorded by observers, and all sightings by the crew in the helicopter were recorded and made available for analysis.

Finally, search in general does not appear to have been independent of the abundance of dolphins associated with tunas. The ZIP-NB index and a nominal CPUE index for yellowfin tuna, computed from the same general data set, show a similar saw-toothed pattern (Figure 9), despite the different life histories of the two species. Given that the percentage of sightings leading to sets was fairly constant through time for each detection type (Figure 3b), and high overall (83.3\%), the ZIP-NB index may actually be an index of the tuna-dolphin association, largely reflecting fishermen's ability to locate areas where dolphins were associated with tunas, instead of indexing changes in the absolute abundance of dolphins. During periods when tuna abundance was high, most dolphin herds may have been associated with tunas and fishing would have been more efficient in areas with high dolphin density where less effort would have been expended to find dolphin herds. On the other hand, when tuna abundance was low, fishermen would have had to work harder to find areas where dolphins were associated with tunas, which may have included areas of low dolphin abundance, increasing effort and decreasing the index. The agreement between dolphin and tuna indices transcends model types fitted to the dolphin data, and subsets of the data. There is agreement between the ZIP-NB index and an index for the northeastern $^{4}$ stock of offshore spotted dolphin (Lennert-Cody et al., 2001) (Figure 9), which was based on line-transect analysis of data from trips with $5 \%$ or more of their sets on tunas associated with dolphins and that used only those sightings within $5 \mathrm{~nm}$ of the vessel. And, there is aggrement between the ZIP-NB index and a preliminary index for the northeastern offshore spotted dolphin based on delta-lognormal model and trips with $5 \%$ or more of sets on tunas associated with dolphins (Lennert-Cody and Maunder, 2014) (Figure 9). The dolphin tuna-vessel indices show some similiarity to the NMFS survey estimates, but the temporal sparseness of the NMFS survey points makes detailed comparison impossible, and errors on the survey estimates are large (Gerrodette et al., 2008). This problem of non-random search with respect to the tunadolphin association is not likely to be remedied by collection of additional sighting and effort

\footnotetext{
${ }^{4}$ The northeastern stock of offshore spotted dolphin is defined geographically as occurring north of $5^{\circ} \mathrm{N}$ and east of $120^{\circ} \mathrm{W}$.
} 
data in the vicinity of the tuna vessel.

It is noted that an alternative interpretation could be taken with regard to the longer time scale similarity of dolphin and tuna indices. On long time scales and over large spatial scales, both species might be expected to be affected similarly by environmental change because both species are large pelagics inhabiting the same ecosystem. Changes in yellowfin tuna diet in the ETP on decadal scales (Olson et al., 2014), and in icthyoplankton assemblages of upwelling areas of the ETP during El Niño events and warm periods (Vilchis et al., 2009), suggest that large-scale spatial-temporal effects of climate change in the ETP have the potential to affect pelagic species by way of changes to the food web. Thus, on certain spatial and temporal scales, some degree of correlation between indices for the two species might be expected because of environmental forcing. Similarities between the two indices, therefore, likely reflect a combination of factors. Unfortunately, not enough is known about the tuna-dolphin association, or its relationship to absolute abundance of dolphins, to be able to quantify environmental effects on the association.

This analysis has highlighted one of the disadvantages of fishery-dependent observer data in the case of associated bycatch species: unless it is known how abundance of the population varies with the strength of the target species-bycatch species association, and with the abundance of the target species, the index of relative abundance for associated animals is difficult to interpret. In the case of dolphins in the ETP, development of an index is particularly problematic. Typically, in stock assessment modeling, a questionable index can be identified by its lack of agreement with other inputs to the assessment model, such as catch amounts and biological parameters. In the case of ETP dolphins, however, both the historical catch and the population growth rate are subject to much debate (NRC, 1992; Wade, 1995; Punt, 2013). Thus, alternatives to indices from fishery-dependent observer data need to be considered, such as those proposed below.

\section{Alternatives to fishery-dependent trends}

\subsection{Line-transect surveys using purse-seine vessels}

The use of large purse-seine vessels from the international tuna fleet as dedicated fisheryindependent survey platforms for conducting dolphin line-transect surveys is one alternative to the use of fishery-dependent data. It is not clear, however, that this option would be any more cost-effective than using dedicated research vessels. The single largest cost component of linetranect surveys in the ETP has been the cost of the vessel (IATTC, 2014 and references therein). The estimated daily cost of a NOAA research vessel in 2013 (including crew) was US\$ 15,000, or, including 25 days in port per vessel, US\$ 4.35 million for a 240 -sea day, 2-vessel survey (which was the survey period used in the latest NMFS ETP survey). For large purse-seine vessels, exact costs will depend on the size and age of the vessel, on country-specific costs of fuel and insurance, and on helicopter costs (for vessels with helicopters). As an example, it is estimated that a large purse-seiner could cost between about US\$15,500 and 25,200 per day. Because the vessels would need to follow strict survey protocols and use pre-determined track lines, just as is done by research vessels (Gerrodette et al., 2008), there would be no opportunity to offset vessel costs with tuna-fishing activities, unless the surveys were conducted in the closed season (see below) and fishing was explicitly built into the survey design to avoid biasing the survey results. 
There is the possibility of conducting dolphin surveys during fishery closures, which might provide a cost savings. Fishery closures for the ETP purse-seine fishery take place between about July and December (IATTC, 2013), around the same time of year as the NOAA surveys were previously conducted. The fishery closures currently consist of two approximately 2 -month closure periods, and each vessel participates in only one of those closures per year. A very rough estimate of the potential of fishing to offset survey costs can be obtained as follows. Based on a price of roughly US\$2,000 per ton of yellowfin tuna (FAO, 2014; 2015; tuna prices are highly variable), and the most recent fishery statistics (IATTC, 2015), which indicate an overall catch per set of yellowfin tuna of about $15 \mathrm{mt}$ in sets on tunas associated with dolphins, it is clear that allowing fishing during a dedicated survey trip would have the potential to offset survey costs. On the other hand, it must be considered whether surveys conducted during a fishery closure, even without allowing limited fishing, would result in sufficient numbers of sightings per purse-seine vessel to allow for standardization of differences among vessels. Roughly 200 sightings of offshore spotted dolphins and eastern spinner dolphins were obtained from the 2006 NMFS survey, with two research vessels operating for a 4-month period (Gerrodette et al., 2008). All else being equal, this number of sightings is at most twice the number of sightings per vessel recommended to be able to standardize for differences in survey platform characteristics and in environmental conditions, although it may be possible to standardize with somewhat fewer sightings using a multiple-covariate distance sampling method (Thomas et al., 2010). This suggests that perhaps 3-4 purse-seine vessels operating for less than 4 months might be feasible, but this is far from certain without a detailed study of previous survey variability. Because purse-seine vessels that fish on tunas associated with dolphins carry helicopters, the use of helicopters as a survey platform could be built into the survey design, perhaps increasing survey effort. Using the same vessels each year would help with issues related to standardization. If, on the other hand, large numbers of purseseine vessels were to survey for short periods of time during a closure, it is unlikely that the number of sightings per vessel would be sufficient to make standardizing for differences among vessels possible, and these differences would result in greater uncertainty in the estimates of abundance. Regardless, there is no guarantee that an index based on tuna vessel line-transect survey data could be delevoped, no matter the cost.

In addition to cost, large-scale line-transect surveys involve considerable logistical and technical overhead. For the NMFS ETP dolphin surveys (e.g., Gerrodette et al., 2008) each vessel carried a seven-person search team, comprised of a scientific coordinator and two teams of three observers, highly skilled and experienced at sighting and identifying marine mammal species. Data for each sighting were entered into a customized computer database in real time, with the position recorded automatically from the survey vessel's Global Positioning System. Observer estimates of dolphin herd size were individually calibrated using aerial photographs collected during the surveys. While it may be possible, after additional training, to use tuna vessel observers as survey observers, most fisheries observer programs are unlikely to be equipped a priori with resources to provide the additional support that large-scale line-transect surveys require.

An important consideration is whether indices of dolphin abundance based on purse-seine vessel surveys should stand alone or could be used to extend the previous research vessel survey estimates. The NMFS ETP surveys were designed to estimate absolute abundance. In principle, if the bias is low, they can be compared with any other low-bias estimates of abundance, while taking the estimation uncertainty into consideration. This has the advantage that any new method 
to estimate absolute abundance does not have to follow the same protocol, only that it is a lowbias, and preferably a low-variance, estimate of absolute abundance. However, if the estimates are biased in the sense that they only provide information on relative abundance, then the same protocol should be used or some form of calibration (standardization) should be conducted. Importantly, if there is no overlap in time between the two survey types (research versus tuna vessel), it will not be possible to standardize for any indirect (or direct) differences in effects of the two survey platforms; any differences attributable to vessel types cannot be unequivocally separated from changes over time in dolphin abundance. This could be an important consideration if, for example, dolphin herds respond differently to tuna vessels (e.g., level of evasive response) compared to research vessels (Pryor and Norris, 1978; Au and Perryman, 1982; Hewitt, 1985; Lennert-Cody and Scott, 2005). Also, although there is overlap between the area covered by the NMFS survey (Gerrodette et al., 2008) and the area covered by the fishery (Figure 1), with considerable overlap between the area of most intense fishing effort and the primary area of focus of the NMFS surveys (north of $5^{\circ} \mathrm{N}$ and east of $120^{\circ} \mathrm{W}$, which corresponds to the northeastern stock of offshore spotted dolphin), the mean spotted dolphin herd size reported by tuna vessels is about 4 times larger than that reported by research vessels. This difference may be due to differences in how the two types of vessels operate but also in how observers on the two types of vessels approach the difficult problem of estimating dolphin herd size (Ward, 2005). It is also worth noting that since the main goal of any survey is to detect changes in abundance and these changes occur slowly over time, creating a new index of relative abundance will not be beneficial in the short term.

\subsection{Alternatives to line-transect surveys}

\subsubsection{Mark-recapture methods}

Abundance can also be estimated using mark-recapture techniques, although large population size, combined with heterogeneous and non-independent probabilities of capture, will make this challenging. Marking individuals with visual tags requires an initial capture to attach the tag to the animal, and subsequent visual "recaptures" of tagged individuals by observers or vessel crew. Tagging and tracking studies of dolphins using radio tags and visual tags (see tag descriptions: White et al., 1981; Scott et al., 1990; Scott and Chivers, 2009) have been conducted previously in the ETP (Perrin et al., 1979; Leatherwood and Ljungblad, 1979; Butler and Jennings, 1980; Scott et al., 1990; Scott and Chivers, 2009), and while much was learned about behavior, movements, and migration patterns, the number of tag returns was not large enough to estimate abundance. Tagging methodology has improved, but further discussion and investigation is needed to determine how radio and visual tagging methods could be applied on a large scale to ETP dolphins for the purpose of monitoring abundance. Also, there is the need to accurately estimate the level of tag losses and heterogeneity of sighting probabilities to help determine the required sample size, and to correct for biases in the population estimate.

Passive Integrated Transponder (PIT) tags are another tagging option to estimate population size (Smyth and Nebel, 2013, and references therein), and have been proposed previously for studying ETP dolphin movement (IATTC, 2005). An animal is "marked" when the PIT tag is implanted internally (thus reducing tag loss) and "resighted" when a receiver detects the presence of the PIT tag during a purse-seine set. Research would be required to determine the viability and practicality of PIT tags for estimating population size using mark-recapture methods, and of using PIT tags in the 
marine environment where tag detection would need to occur over a distance of several meters. However, PIT tags have a potential advantage because the dectector could be located in the cork line of the purse-seine net, over which dolphins pass when they are released during the "backdown" procedure prior to brailing the tuna (NRC, 1992). This would allow for recaptures that did not interfere with fishing operations nor require time of vessel crew and fisheries observers. Thus, the use of PIT tags could take direct advantage of the fishing process to obtain recaptures. Spatiallyexplicit capture-recapture models (Borchers, 2012) might perform well with this type of data.

Genetic mark-recapture techniques (e.g., Pearse et al., 2001) and "close-kin analysis" methods (e.g., Skaug, 2001; Bravington et al., 2014), use genetic information to estimate abundance. Mark-recapture methods require an initial sample for marking and a subsequent recapture sample. Close-kin methods require sampling of both adults and calves, and the tendency of cows and calves to associate (Scott and Perryman, 1998) may pose a challenge to the use of this method unless the association can be modelled. Based on the 2006 estimates of dolphin abundance of about 1.3 million offshore spotted dolphins (Gerrodette et al., 2008), tissue samples from roughly 17,000 offshore spotted dolphins (per Robson and Regier, 1964) would need to be collected during each phase for the mark-recapture study. For close-kin analysis, using the abundance and coefficient of variation from the 2006 surveys (Gerrodette et al., 2008) and the sample size formula of Bravington et al. (2014), samples from about 9,000 animals would be required in the first year, but perhaps fewer samples in subsequent years. Using the maximum number of animals biopsied during the NMFS CHESS cruises (27 animals in one dolphin-set; Forney et al., 2002), and assuming 1 dolphin-set per day, genetics sampling using the close-kin method would require over 330 dedicated sea-days, and more for the genetics mark-recapture method; the number of sea days may be greater if non-independence of captures from the same set cannot be addressed analytically. This number of sea days is greater than the 240 sea-days estimated for the NMFS line-transect surveys. For close-kin methods, and for recaptures for the mark-recapture method, it may be possible to obtain samples from dead animals only, but at the current annual mortality level of about 1,000 animals (IATTC, 2013), it would take a decade or more to obtain sufficient samples. Nonetheless, these samples could still be valuable in the long run. Alternatively, recaptures for the genetics mark-recapture method might be obtained from tissue samples collected by vessel crew or fisheries observers from live animals at the time that dolphins are released from the purse-seine net in the backdown procedure during normal fishing operations. Vessel crew are in the water at the time of backdown, in rafts and as swimmers, to help release dolphins from the net (NRC, 1992). The median number of spotted dolphins encircled with the purse-seine net in a set during 1994-2013 was 230 animals (IATTC, unpublished data). If even a small fraction of those animals could be successfully sampled, at the current level of about 10,000 dolphin sets per year (IATTC, 2015), reaching the required number of recaptures in several years may be feasible. Thus, for ETP dolphins, genetic mark-recapture may be more advantageous than close-kin genetic methods because marks and recaptures can be for any individuals, and therefore the sampling could make direct use of the fishing process.

Mark-recapture methods that take advantage of the fishing process, such as PIT tags and genetics mark-recapture, would seem most promising from the point of view of maximizing data collection with minimal interruption to daily fishing activities. For all these mark-recapture methods, however, there are research costs that have yet to be determined, as well as costs for logistics and technical support, and analysis, and so it is not presently clear how mark-recapture 
methods compare to line-transect methods in terms of cost. Moreover, genetics markers for dolphin species would need to be developed.

For all mark-recapture methods, if implemented during normal fishing operations, it would be essential to establish that animals encountered by fishery are representative of the population; i.e., that it is not just a specific subset of the dolphin population that gets encircled by purseseines. Because the purpose of fishing is to catch fish, fishermen attempt to encircle dolphins that are associated with tuna, which may not be the entire dolphin herd (NRC, 1992). Prior to encirclement with the purse-seine net, fishermen attempt to exclude dolphins not associated with tunas and some dolphins actively evade capture. Spatial structure in dolphin evasive response (e.g., Lennert-Cody and Scott, 2005), for example, implies that recapture probabilities would not be expected $a$ priori to be spatially invariant.

\subsubsection{Life history sampling}

Life history data were collected by NMFS and IATTC observers from the 1970 s to the mid1990s (e.g., Perrin et al., 1973; Perrin et al., 1976; Perrin and Henderson, 1984; Perrin and Reilly, 1984; Hohn and Hammond, 1985; Hohn et al., 1985; Myrick et al., 1986; Perrin and Hohn, 1994; Galván-Magaña, 1999; Olson and Watters, 2003; Scott et al., 2012). Observers recorded information on length, sex, and color phase in spotted dolphins (an indicator of age class: Perrin, 1970) from dolphins that died in purse-seine sets, and collected reproductive organs, stomach contents, and teeth (for estimating age). Although observers continue to collect data on color phase, routine collection of other life history data ended due to insufficient funding. The IATTC has approved resumption of a complete life history sampling program (IATTC, 2005), but funding has yet to be procured.

Life history data, without ongoing surveys, cannot provide an estimate of relative abundance, but over time, such data can offer qualitative information on population status, and life history data have been used extensively in studies of ETP dolphin stock status. Reilly and Barlow (1986) used survivorship and fecundity data (calving interval, age at first birth, adult and juvenile survivorships) to calculate maximum population growth rates, which have been used for stock assessment and management of marine mammals under the U.S. Marine Mammal Protection Act (Wade, 1998; MMPA, 2004). Age structure information has been used to make inference about population status, including evaluation of whether there are "holes" in the age distribution indicative of age-biased take (Chivers, 2002; Archer and Chivers, 2002; Reilly et al., 2005). Agestructured models, which incorporate life history information, have been used to assess ETP dolphin populations (Wade, 1994; Hoyle and Maunder, 2004; Reilly et al., 2005). Moreover, existing estimates of historical reproductive rates, survival rates, and age distributions (e.g., Perrin et al., 1973; Perrin et al., 1976; Perrin and Henderson, 1984; Perrin and Reilly, 1984; Hohn and Hammond, 1985; Hohn et al., 1985; Myrick et al., 1986; Perrin and Hohn, 1994; Perrin and Gilpatrick, 1994) could be compared with similar estimates from future life history sampling programs.

As with any data source, collection of life history data has both advantages and disadvantages. One advantage of life history data is that the cost of data collection is relatively low. The approximate cost of life history sampling for ETP dolphins would be US\$ 255,000 for the first few years, but would likely decrease in subsequent years. And, the sampling can be done by 
observers already aboard tuna vessels. Life history sampling would therefore directly take advantage of the fishing process. One disadvantage is that, because current dolphin mortality is so low, the data collection would need to be long-term and continuous to 1) gather a sample size adequate to compare with older data, and 2) provide ongoing monitoring of population parameters in the future. Another disadvantage, as noted above, is that life history data alone can only provide qualitative information on population status.

\section{Conclusions}

Indices of relative abundance computed from fishery-dependent observer data for species such as ETP dolphins, which are directly associated with the fishing process, are unlikely to be reliable indicators of absolute abundance trends. Attempts to develop an index of dolphin relative abundance from the current purse-seine data will be handicapped by a lack of independence of search effort and searching behavior, and the abundance of dolphin herds associated with tunas, as well as a lack of detailed data on activities of helicopter search and sightings. On the other hand, purse-seine vessels may serve as useful scientific platforms for estimating abundance based on other methods. Although purse-seine vessels may not be any more cost effective than research vessels for line-transect surveys, they may offer opportunities for mark-recatpure methods that take advantage of the fishing process to obtain recaptures. These mark-recapture methods will require a research and development phase, and are thus unlikely to provide information on abundance in the short term. The issues raised here with respect to dolphin trend estimation from fishery-dependent data underscore the need for basic research on the dynamics of the tuna-dolphin bond and the connection between abundance of dolphin associated with tunas and total dolphin population size.

\section{Acknowledgements}

Special thanks to Ernesto Altamirano, Enrique Ureña, and Nickolas Vogel for helpful discussion on tuna-vessel fishing behavior, to Lisa Ballance and Brad Wiley for providing the vessel cost estimates, to Nickolas Vogel for helpful discussions on computation of searching effort and database assistance, to Christine Patnode for graphics assistance and to Richard Deriso for suggesting Wald's equation. Special thanks to Lisa Ballance, Richard Deriso, Elizabeth Edwards, Jeffrey Moore, Andre Punt, Hans Skaug and an anonymous reviewer for reviewing this manuscript and providing helpful comments that greatly improved the manuscript.

\section{References}

Agreement for the International Dolphin Conservation Program (AIDCP), 2005. $14^{\text {th }}$ Meeting of the parties: Minutes of the meeting, 20 October 2005. La Jolla, CA, USA. http://www.iattc.org/PDFFiles2/MOP-14-Minutes-Oct-2005.pdf

Anganuzzi, A.A. and Buckland, S.T., 1989. Reducing bias in trends in dolphin relative abundance, estimated from tuna vessel data. Rep. Intern. Whal. Comm. 39, 323-334.

Archer F., and Chivers, S.J., 2002. Age structure of the northeastern spotted dolphin incidental kill by year for 1971 to 1990 and 1996 to 2000. Southwest Fisheries Science Center Administrative Report LJ-02-12.

https://swfsc.noaa.gov/uploadedFiles/Divisions/PRD/Programs/ETP_Cetacean_Assessment/LJ_0 2_12.pdf

Au, D.W.K., and Perryman, W., 1982. Movement and speed of dolphin schools responding to an 
approaching ship. Fish. Bull. 80, 371-379.

Barlow, J., 2015. Inferring trackline detection probabilities, $\mathrm{g}(0)$, for cetaceans from apparent densities in different survey conditions. Mar. Mamm. Sci. 31, 923-943.

Borchers, D., 2012. A non-technical overview of spatially explicit capture-recapture models. J. of Ornithol. 152, S435-S444.

Bravington, M.V., Grewe, P.M., Davies, C.R., 2014. Fishery-independent estimate of spawning biomass of Southern Bluefin tuna through identification of close-kin using genetic markers. Fisheries Research \& Development Corporation Report No. 2007/034, March 2014. CSIRO, Australia. http://frdc.com.au/research/Documents/Final_reports/2007-034-DLD.pdf

Buckland, S.T. and Anganuzzi, A.A., 1988. Estimated trends of abundance of dolphins associated with tuna in the eastern Tropical Pacific. Rep. Intern. Whal. Comm. 38, 411-437.

Buckland, S.T., Cattanach, K.L., Anganuzzi, A.A., 1992. Estimating trends in abundance of dolphins associated with tuna in the eastern tropical Pacific Ocean, using sightings data collected on commercial tuna vessels. Fish. Bull. 90, 1-12.

Burnham, K.P., Anderson, D.R., 2002. Model Selection and Multimodel Inference: A Practical Information-Theoretic Approach, Second Edition. Springer.

Butler, R.W., and Jennings, J.G., 1980. Radio tracking of dolphins in the eastern tropical Pacific using VHF and HF equipment, in: Amlaner, Jr., C.J., and MacDonald, D.W. (Eds.), A Handbook on Biotelemetry and Radio tracking, Pergamon Press, Oxford, pp. 757-759.

Chivers, S.J., 2002. Age structure of female eastern spinner dolphins (Stenella longirostris orientalis) incidentally killed in the eastern tropical Pacific tuna purse-seine fishery. Southwest Fisheries Science Center Administrative Report LJ-02-11.

https://swfsc.noaa.gov/uploadedFiles/Divisions/PRD/Programs/ETP_Cetacean_Assessment/ LJ_02_11.pdf

Dempster, A.P., Laird, N.M., Rubin, D.B., 1977. Maximum likelihood from incomplete data via the EM algorithm (with discussion). J. R. Stat. Soc. B 39, 1-38.

FAO, 2014. Food and Agriculture Organization of the United Nations GLOBEFISH Newletter for November, 2014. http://www.globefish.org/tuna-october-2014.html

FAO, 2015. Food and Agriculture Organization of the United Nations GLOBEFISH Newsletter for April, 2015. http://www.globefish.org/tuna-march-2015.html

Forney, K.A., St. Aubin, D.J., Chivers, S.J., 2002. Chase encirclement stress studies on dolphins involved in eastern tropical Pacific Ocean purse-seine operations during 2001. Administrative Report LJ-02-32. La Jolla: Southwest Fisheries Science Center. https://swfsc.noaa.gov/uploadedFiles/Divisions/PRD/Programs/ETP_Cetacean_Assessment/ LJ_02_32.pdf

Galván-Magaña, F., 1999. Relaciones tróficas interspecíficas de la comunidad de depredadores epipelágicos del Océano Pacífico oriental. Doctoral thesis, Centro de Investigación Científica y de Educación Superior de Ensenada, Ensenada, México.

Gerrodette, T., and Forcada, J., 2005. Non-recovery of two spotted and spinner dolphin populations in the eastern tropical Pacific Ocean. Mar. Ecol. Prog. Ser. 291, 1-21.

Gerrodette, T., Watters, G., Perryman, W., Ballance, L., 2008. Estimates of 2006 dolphin abundance in the eastern tropical Pacific, with revised estimates for 1986-2003. NOAA-TMNMFS-SWFSC-422. https://swfsc.noaa.gov/publications/TM/SWFSC/NOAA-TM-NMFSSWFSC-422.PDF

Hall, M., García, M., Lennert-Cody, C., Arenas, P., and Miller, F., 1999. The association of 
tunas with floating objects and dolphins in the eastern Pacific Ocean: A review of the current purse-seine fishery, in: Scott, M., Bayliff, W.H., Lennert-Cody, C.E., and Schaefer, K.M., (Eds.), Proceedings of the International Workshop on the Ecology and Fisheries for Tunas Associated with Floating-objects, February 11-13, 1992. Inter-Am. Trop. Tuna Comm. $\quad$ Special $\quad$ Report 11. http://www.iattc.org/PDFFiles2/SpecialReports/SpecialReport11.pdf

Hewitt, R.P., 1985. Reaction of dolphins to a survey vessel: effects on census data. Fish. Bull.z.83, 187-193.

Hohn, A.A., and Hammond, P.S., 1985. Early postnatal growth of the spotted dolphin, Stenella attenuata, in the offshore eastern tropical Pacific. Fish. Bull. 83, 553-566.

Hohn, A.A., Chivers, S.J., Barlow, J., 1985. Reproductive maturity and seasonality of male spotted dolphins, Stenella attenuata, in the eastern tropical Pacific. Mar. Mamm. Sci. 1, 273293.

Hoyle, S.D. and Maunder, M.N., 2004. A Bayesian integrated population dynamics model to analyze data for protected species. Anim. Biodivers. Conserv. 27, 247-266.

IATTC, 2005. IATTC Scientific Advisoty Board Document SAB-2-08a. $2^{\text {nd }}$ Meeting of the Scientific Advisory Board, 19 June, 2005, Lanzarote, Spain. http://www.iattc.org/PDFFiles2/SAB-2-08a-Dolphin-tagging.pdf

IATTC, 2006. Technical workshop on calculating $\mathrm{N}_{\min }$ for the dolphin stocks of the eastern Pacific Ocean. Inter-Am. Trop. Tuna Comm Special Report 14.

IATTC, 2013. Inter-American Tropical Tuna Commission Annual Report for 2009. http://www.iattc.org/PDFFiles2/AnnualReports/IATTC-Annual-Report-2009.pdf

IATTC, 2014. Options for assessing the status of dolphin populations in the eastern Pacific Ocean. Document MOP-30 INF-A. Inter-Am. Trop. Tuna Comm 30 ${ }^{\text {th }}$ Meeting of the Parties, La Jolla $\quad$ California, $26 \quad$ October, 2014. http://www.iattc.org/Meetings/Meetings2014/OCT/PDFs/MOP-30-INF-A-Options-fordolphin-population-assessments.pdf

IATTC, 2015. Inter-American Tropical Tuna Commission Fishery Status Report 13. http://www.iattc.org/FisheryStatusReportsENG.htm

Lennert-Cody, C.E. and Scott, M.D., 2005. Spotted dolphin evasive response in relation to fishing effort. Mar. Mamm. Sci. 21, 13-28.

Lennert-Cody, C.E. and Maunder, M.N., 2014. Progress report on development of an index of relative abundance for dolphins from purse-seine observer data. Inter-Am. Trop. Tuna Comm Document SAC-05-11d, $5^{\text {th }}$ Meeting of the Scientific Advisory Committee, 12-16 May, 2014, La Jolla, California, USA. http://www.iattc.org/Meetings/Meetings2014/MAYSAC/PDFs/SAC-05-11d-Dolphinabundance-index.pdf

Lennert-Cody, C.E., Buckland, S.T., Marques, F.C., 2001. Trends in dolphin abundance estimated from fisheries data: A cautionary note. J. of Cetacean Res. and Manag. 3, 305319.

Maunder, M.N. and Punt, A.E., 2004. Standardizing catch and effort data: a review of recent approaches. Fish. Res. 70, 141-159.

Maunder, M.N., Silbert, J.R., Fonteneau, A., Hampton, J., Kleiber, P., and Harley, S.J., 2006. Interpreting catch per unit effort data to assess the status of individual stocks and 
communities. ICES J. Mar. Sci. 63, 1373-1385.

McLachlan, G.J., Krishnan, T., 2008. The EM algorithm and Extensions, $2^{\text {nd }}$ Edition. Wiley.

Minami, M., Lennert-Cody, C.E., Gao, W., Román-Verdesoto, M., 2007. Modeling shark bycatch: The zero-inflated negative binomial regression model with smoothing. Fish. Res. 84, 210-221.

MMPA, 2007. The Marine Mammal Protection Act of 1972 as amended 2007. http://www.nmfs.noaa.gov/pr/pdfs/laws/mmpa.pdf

Myrick, A.C., Jr., Hohn, A.A., Barlow, J., Sloan, P.A., 1986. Reproductive biology of female spotted dolphins, Stenella attenuata, from the eastern tropical Pacific. Fish. Bull. 84, 247259.

National Research Council (NRC), 1992. Dolphins and the tuna industry. National Academy Press, Washington, D.C.

Olson, R.J., Duffy, L.M., Kuhnert, P.M., Galván-Magaña, F., Bocanegra-Castillo, N., AlatorreRamírez, V., 2014. Decadal diet shift in yellowfin tuna Thunnus albacares suggests broadscale food web changes in the eastern tropical Pacific Ocean. Mar. Ecol. Prog. Ser. 497, 157-178.

Olson, R.J., and Watters, G.W., 2003. A model of the pelagic ecosystem in the eastern tropical Pacific Ocean. Inter-Am. Trop. Tuna Comm. Bull. 22,135-218.

Pearse, D.E., Eckerman, C.M., Janzen, F.J., Avise, J.C., 2001. A genetic analogue of 'markrecapture' methods for estimating population size: An approach based on molecular parentage assessments. Mol. Ecol. 10, 2711-2718.

Perrin, W.L., 1970. Color pattern of the eastern Pacific spotted porpoise (Stenella graffmani) Lönnberg (Cetacea, Delphinidae). Zool. 54, 135-149.

Perrin, W.F., Warner, R.R., Fiscus, C.H., Holts, D.B., 1973. Stomach contents of porpoise, Stenella spp., and yellowfin tuna, Thunnus albacares, in mixed-species aggregations. Fish. Bull. 71, 1077-1092.

Perrin, W.L., Coe, J.M., Zweifel, J.R., 1976. Growth and reproduction in the spotted porpoise (Stenella attenuata) in the offshore eastern Pacific Ocean. Fish. Bull. 74, 229-269.

Perrin, W.F., Evans, W.E., Holts, D.B., 1979. Movements of pelagic dolphins (Stenella spp.) in the eastern tropical Pacific as indicated by results of tagging, with summary of tagging operations. NOAA Technical Report NMFS SSRF-737.

Perrin, W.F., and Henderson J.R., 1984. Growth and reproductive rates in two populations of spinner dolphins, Stenella longirostris, with different histories of exploitation, in: Perrin, W.F., Brownell Jr., R.L., and DeMaster, D.P. (Eds.), Reproduction in whales, dolphins and porpoises, , Rep. Int. Whal. Comm., Special Issue 6, pp. 417-430.

Perrin, W.F., and Reilly, S.B., 1984. Reproductive parameters of dolphins and small whales of the family Delphinidae, in: Perrin, W.F., Brownell Jr., R.L., and DeMaster, D.P. (Eds.), Reproduction in whales, dolphins and porpoises, , Rep. Int. Whal. Comm., Special Issue 6, pp. 97-133.

Perrin, W.F., and Gilpatrick, J.W., 1994. Spinner dolphin Stenella longirostris, in: Ridgway, S.H. and Harrison, R. (Eds.), Handbook of marine mammals, Volume 5: The first book of dolphins, Academic Press, New York, pp. 99-128.

Perrin, W.F., and Hohn A.A., 1994. Pantropical spotted dolphin Stenella attenuata, in: Ridgway, 
S.H. and Harrison, R. (Eds.), Handbook of marine mammals, Volume 5: The first book of dolphins, Academic Press, New York, p. 71-98.

Pryor, K., and Norris, K.S., 1978. The tuna-porpoise problem: Behavioral aspects. Ocean. 21, 31-37.

Punt, A.E., 2013. Independent review of the eastern Pacific Ocean dolphin population assessment. Inter-Am. Trop. Tuna Comm. Special Report 21. http://www.iattc.org/PDFFiles2/SpecialReports/IATTC-Special-Report-21.pdf

R Development Core Team, 2012. R: A language and environment for statistical computing. R Foundation for Statistical Computing, Vienna, Austria. ISBN 3-900051-07-0, URL http://www.R-project.org/.

Reilly, S.B., and Barlow, J., 1986. Rates of increase in dolphin population size. Fish. Bull. 84, 527-533.

Reilly, S.B., Donahue, M., Gerrodette, T., Forney, K., Wade, P., Ballance, L., Forcada, J. Fiedler, P., Dizon, A. Perryman, W., Archer F., Edwards E., 2005. Report of the scientific research program under the International Dolphin Conservation Program Act. NOAA-TMNMFS-SWFSC-372. https://swfsc.noaa.gov/publications/TM/SWFSC/NOAA-TM-NMFSSWFSC-372.PDF

Robson, D.S. and Regier, H.A., 1964. Sample size in Petersen mark-recapture experiments. Trans. Am. Fish. Soc. 93, 215-226.

Skaug, H.J., 2001. Allele-sharing methods for estimation of population size. Biom. 57, 750-756.

Scott, M.D., and Perryman, W.L., 1998. Using aerial photogrammetry to study dolphin school structure, in: Pryor, K., and Norris, K.S., (Eds.), Dolphin Societies: Discoveries and Puzzles, University of California Press, pp. 227-241.

Scott, M.D., and Chivers, S.J., 2009. Movements and diving behavior of pelagic spotted dolphins. Mar. Mamm. Sci. 25, 137-160.

Scott, M.D., Wells, R.S., Irvine A.B., 1990. A review of tagging and marking studies on small cetaceans, in: Leatherwood, S. and Reeves, R. (Eds.), The Bottlenose Dolphin, Academic Press, San Diego, pp. 489-514.

Scott M.D., Chivers, S.J., Olson, R.J., Fiedler, P.C., Holland, K., 2012. Pelagic predator associations: Tuna and dolphins in the eastern tropical Pacific Ocean. Mar. Ecol. Prog. Ser. 458, 283-302.

Smyth, B. and Nebel, S., 2013. Passive integrated transponder (PIT) tages in the study of animal movement. Nat. Educ. Knowl. 4:3.

Strindberg, S., Buckland, S.T., 2004. Zigzag survey designs in line transect sampling. J. Agric. Biol. Environ. Stat. 9, 443-461.

Thomas, L., Buckland, S.T., Rexstad, E.A., Laake, J.L., Strindberg, S., Hedley, S.L., Bishop, J.R.B., Marques, T.A. and Burnham, K.P., 2010. Distance software: design and analysis of distance sampling surveys for estimating population size. . Appl. Ecol. 47, 5-14.

Vilchis, L.I., Ballance, L.T., Watson, W., 2009. Temporal variability of neustonic ichthyoplankton assemblages of the eastern Pacific warm pool : Can community structure be linked to climate variability? Deep-Sea Res. I 56, 125-140.

Wade, P.R., 1994. Abundance and population dynamics of two eastern Pacific dolphins, Stenella attenuata and Stenella longirostris orientalis. Ph.D. dissertation. Scripps Institution of Oceanography, University of California, San Diego, California, USA. 
Wade, P.R., 1995. Revised estimates of incidental of dolphins (Delphinidae) by the purse-seine tuna fishery in the eastern tropical Pacific, 1959-1972. Fish. Bull. 93, 345-354.

Wade, P.R., 1998. Calculating limits to the human-caused mortality of cetaceans and pinnipeds. Mar. Mamm. Sci. 14, 1-37.

Wade, P.R., Reilly, S.B., and Gerrodette, T. 2002. Assessment of the population dynamics of the northeastern offshore spotted and the eastern spinner dolphin populations through 2002. Southwest Fisheries Science Center Administrative Report LJ-02-13. https://swfsc.noaa.gov/uploadedFiles/Divisions/PRD/Programs/ETP_Cetacean_Assessment/ LJ_02_13(1).pdf

Wade, P.R., Watters, G.M., Gerrodette, T., Reilly S.B., 2007. Depletion of northeastern offshore spotted and eastern spinner dolphins in the eastern tropical Pacific and hypotheses for their lack of recovery. Mar. Ecol. Prog. Ser. 343, 1-14.

Wald, A., 1944. On cumulative sums of random variables. Ann. Math. Stat. 15, 283-296.

Ward, E. J., 2005. Differences between fishery-dependent and fishery-independent estimates of single- and mixed-species dolphin schools: implications for single-species stock assessments. Mar. Mamm. Sci. 21, 189-203.

Watters, G.M., 1999. Geographical distributions of effort and catches of tunas by purse-seine vessels in the eastern Pacific Ocean during 1965-1998. Inter-Am. Trop. Tuna Comm. Data Report 10. http://www.iattc.org/PDFFiles2/DataReports/Data-Report-10.pdf

White, M.J., Jr., Jennings, J.G., Gandy, W.F., Cornell L.H., 1981. Evaluation of tagging, marking, and tattooing techniques for small delphinids. NOAA Technical Memorandum NMFS,

NOAA-TM-NMFS-SWFC-16. https://swfsc.noaa.gov/publications/TM/SWFSC/NOAA-TM-NMFS-SWFC-16.PDF

Wood, S.N., 2006. Generalized Additive Models: An Introduction with R, Chapman and Hall/CRC, Boca Raton.

Yee, W.T., 2014. VGAM: Vector Generalized Linear and Additive Models. R package version 0.9-6. URL http://CRAN.R-project.org/package=VGAM

Zuur, A.F., Ieno, E.N., Walker, N.J., Saveliev, A.A., Smith,G.M., 2009. Mixed Effects Models and Extensions with R, Springer, New York. 
Figure 1. Map of search effort by $1^{\circ}$ area for the ETP (after all data processing), summed over years 1990-2013. Blue: $\leq 576 \mathrm{~km}$; green: $576 \mathrm{~km}-4,422 \mathrm{~km}$; gold: 4,422 - 13,830 km; red: > $13,830 \mathrm{~km}$.

Figure 2. Box-and-whiskers plots of the distance to dolphin sightings from the purse-seine vessel $(\mathrm{nm})$, by detection type and year. The red dashed line shows the overall median distance (helicopter: $12.8 \mathrm{~nm}$; radar: $8.7 \mathrm{~nm}$; binoculars: $5.0 \mathrm{~nm}$ ). Each box indicates the middle $50 \%$ of the data for that year (the black vertical line is the median), circles indicate values beyond 1.5 times the interquartile range from the box.

Figure 3. (a) Percent sightings by detection type, and (b) percent set-sightings by detection-type. The percentage of sightings by detection type is the annual number of sightings by detection type divided by the total annual number of sightings, times 100. The percentage of set-sightings by detection type is the total number of sightings that led to sets for a given search method divided by the annual number of sightings of that detection type, times 100 .

Figure 4. Box-and-whisker plots of the change in the detection variable, $r$, by year.

Figure 5. Box-and-whisker plot of the dolphin herd size by detection type and non-set-sighting versus set-sighting. The $\mathrm{y}$-axis has been truncated at 2000 to show detail.

Figure 6. (a) The smooth term for $\mathrm{km}$ search from the loglinear (Poisson) component of the ZIP regression model, and (b) box-and-whisker plots of $\mathrm{km}$ search (trip-day $1^{\circ}$ area), grouped by the number of set-sightings. The rug at the bottom of figure (a) shows the distribution of values of km search.

Figure 7. (a) The smooth term for the change in the detection variable, $r$, from (a) the logistic component of the ZIP regression model, and (b) from the loglinear component of the ZIP regression model. The 'rug' at the bottom of each figure shows the distribution of values of $r$.

Figure 8. Spatial trajectory of a 50-day fishing trip from 2012. Top panel shows the location of effort; black open circles indicate $1^{\circ}$ areas with effort, size proportional to the amount of effort, and the gray dotted line connects $1^{\circ}$ areas through time. Bottom panel shows some sighting characteristics. Regions of the trip trajectory were subjectively labelled as 'transit' and 'area' search; no quantitative analysis was done of the spatial trajectory for this trip.

Figure 9. Mean-scaled indices of relative abundance for dolphins and tunas. The mean-scaled lower and upper $95 \%$ confidence interval for the 1998 northeastern offshore spotted dolphin estimate (Gerrodette et al., 2008; blue vertical line) is provided to indicate the error associated with the survey estimates of abundance. The year 1998 was selected because the coefficient of variation for the northeastern offshore spotted estimate was the smallest of the period 1990-2006. Confidence intervals for the offshore spotted dolphin estimates and the northeastern offshore spotted dolphin estimates in other years would be larger. 


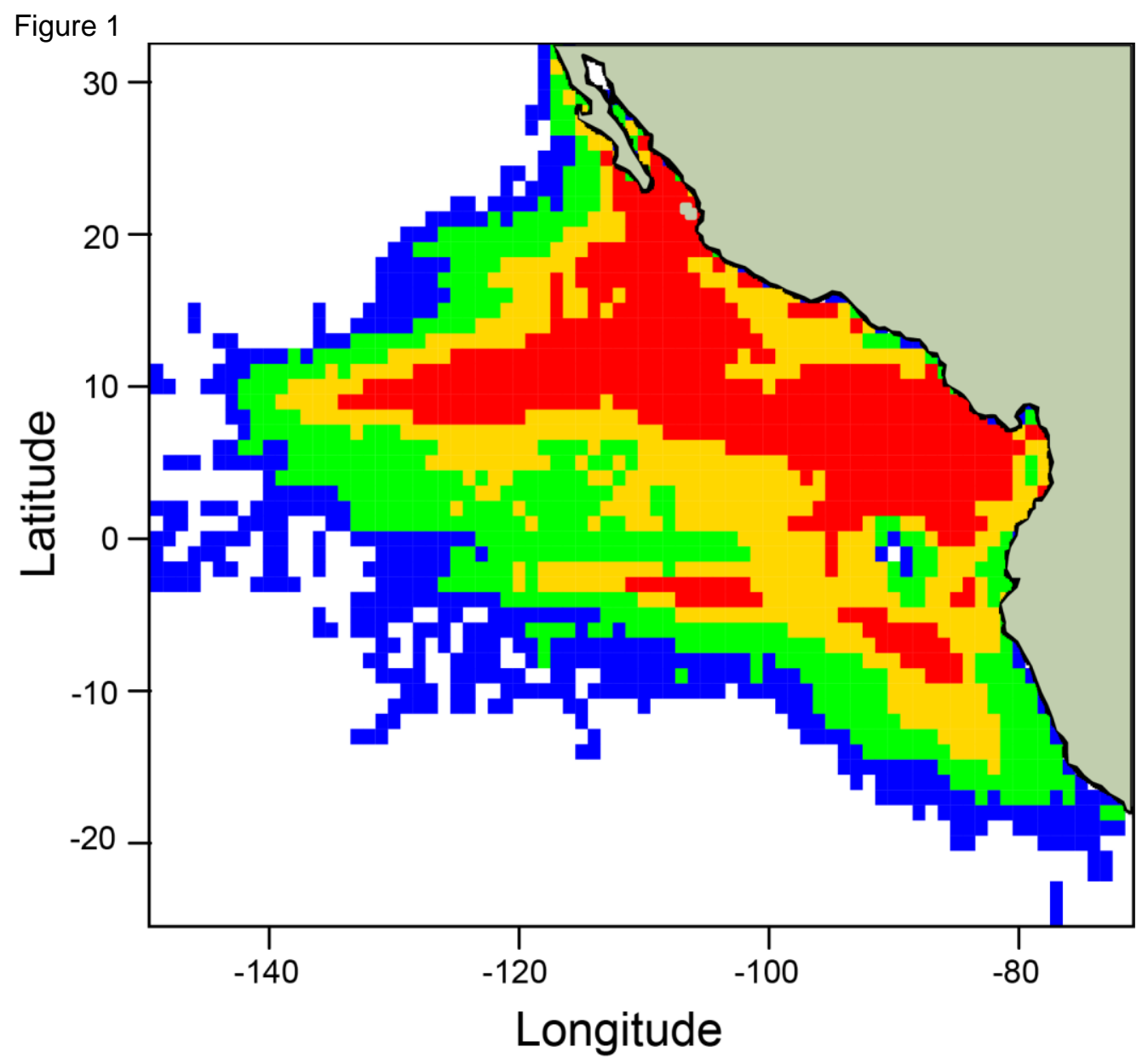


Figure 2
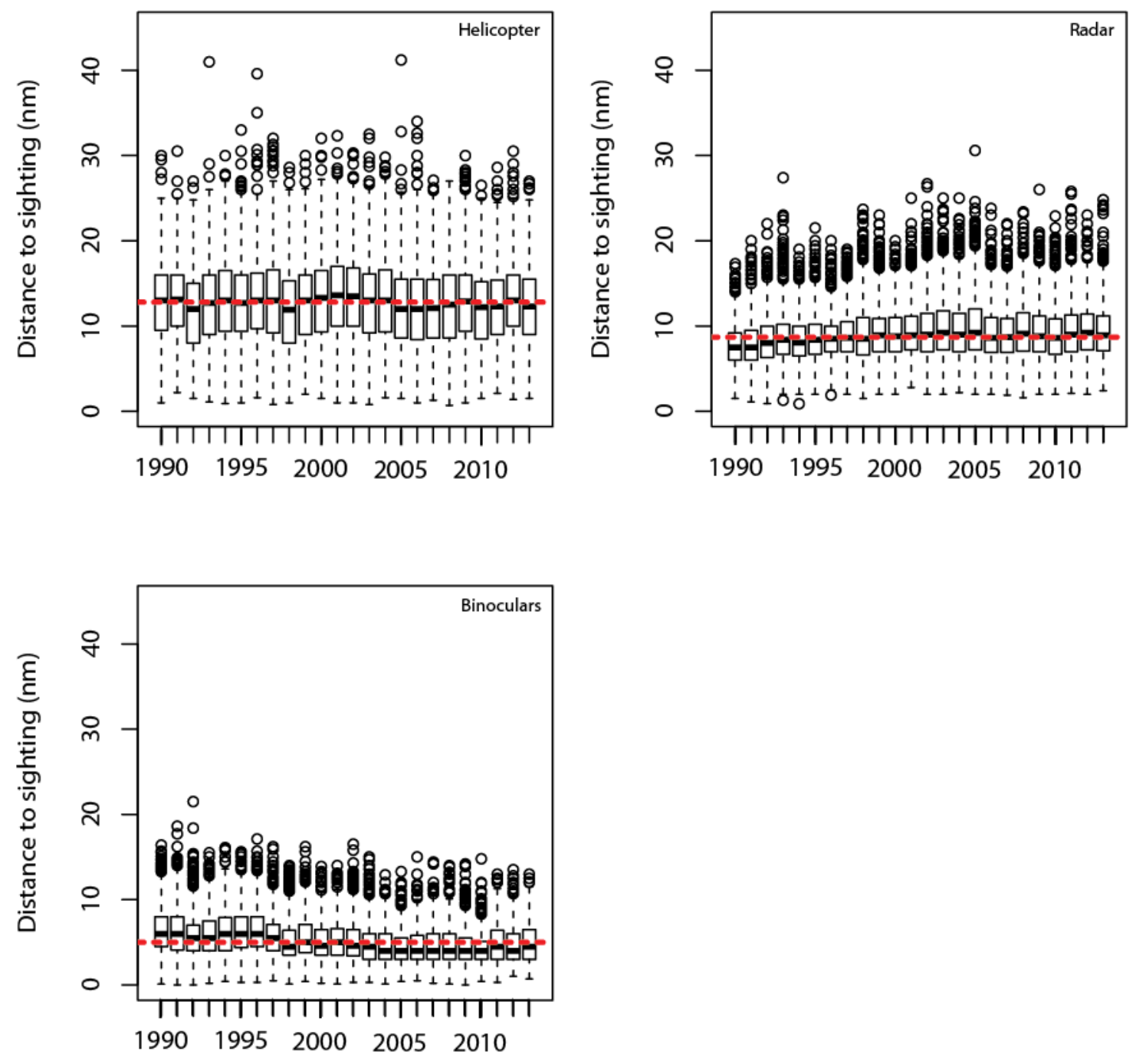
Figure 3
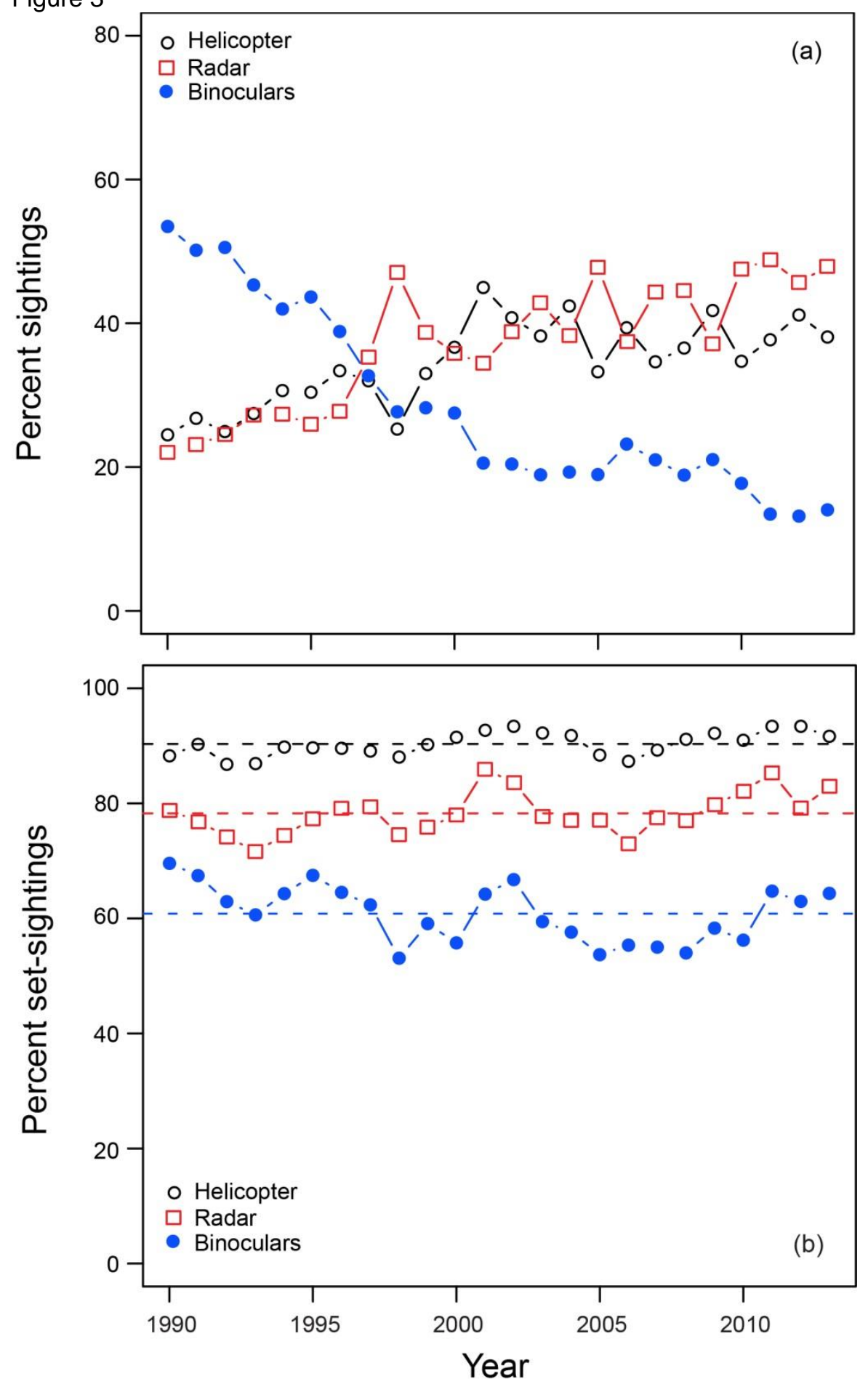


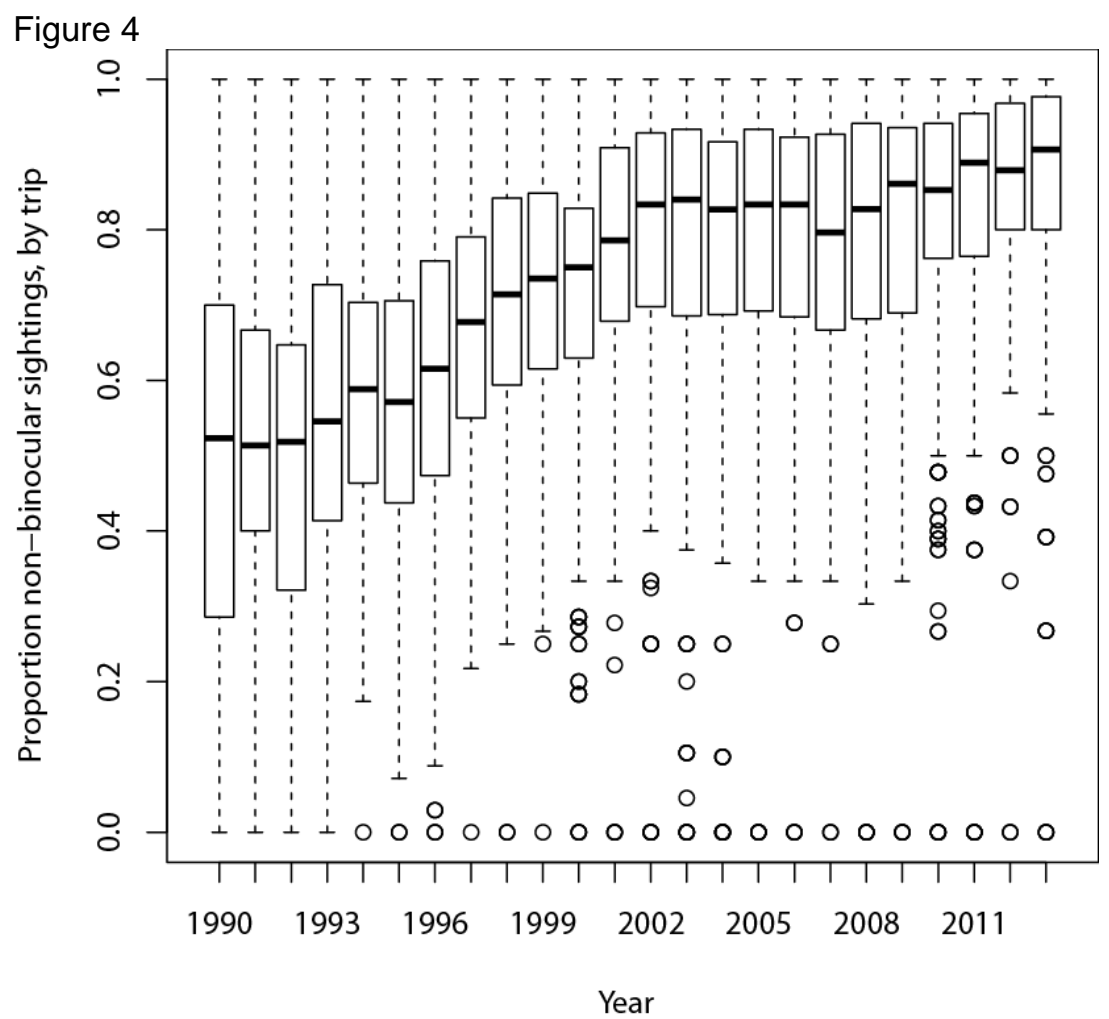


Figure 5

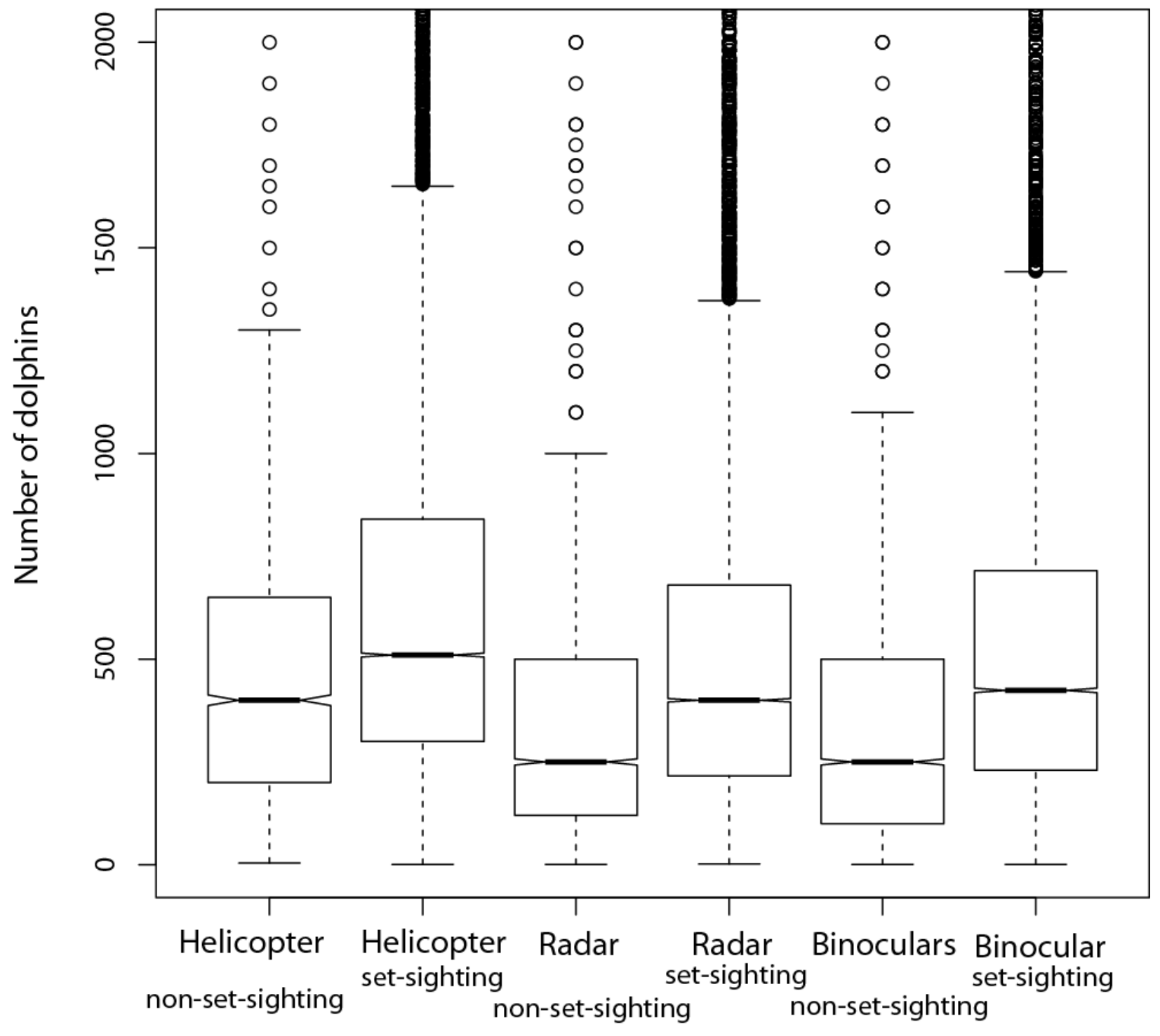



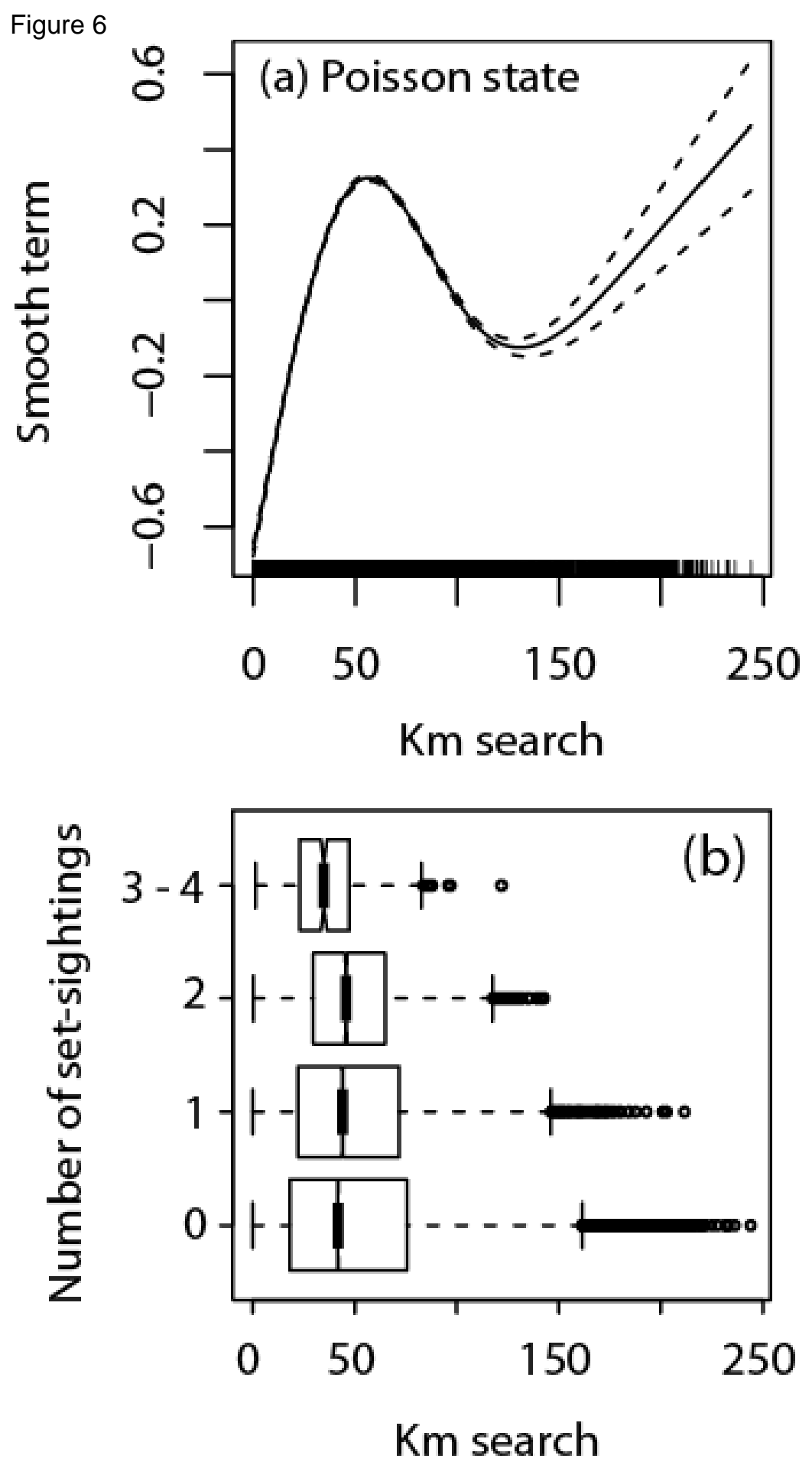


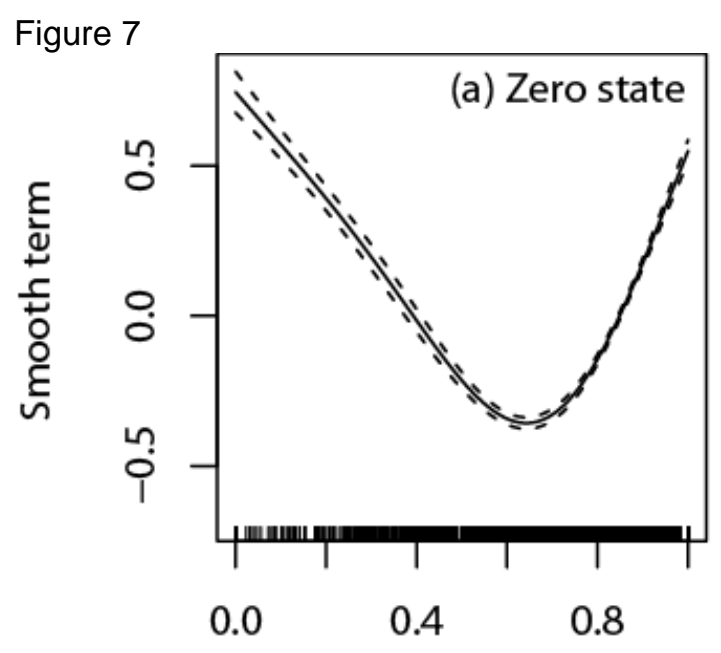

Proportion non-binocular sighting

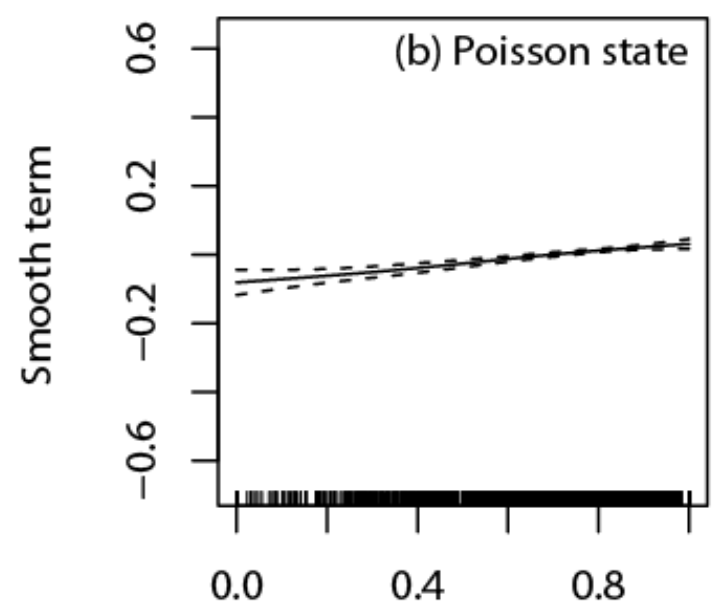

Proportion non-binocular sighting 


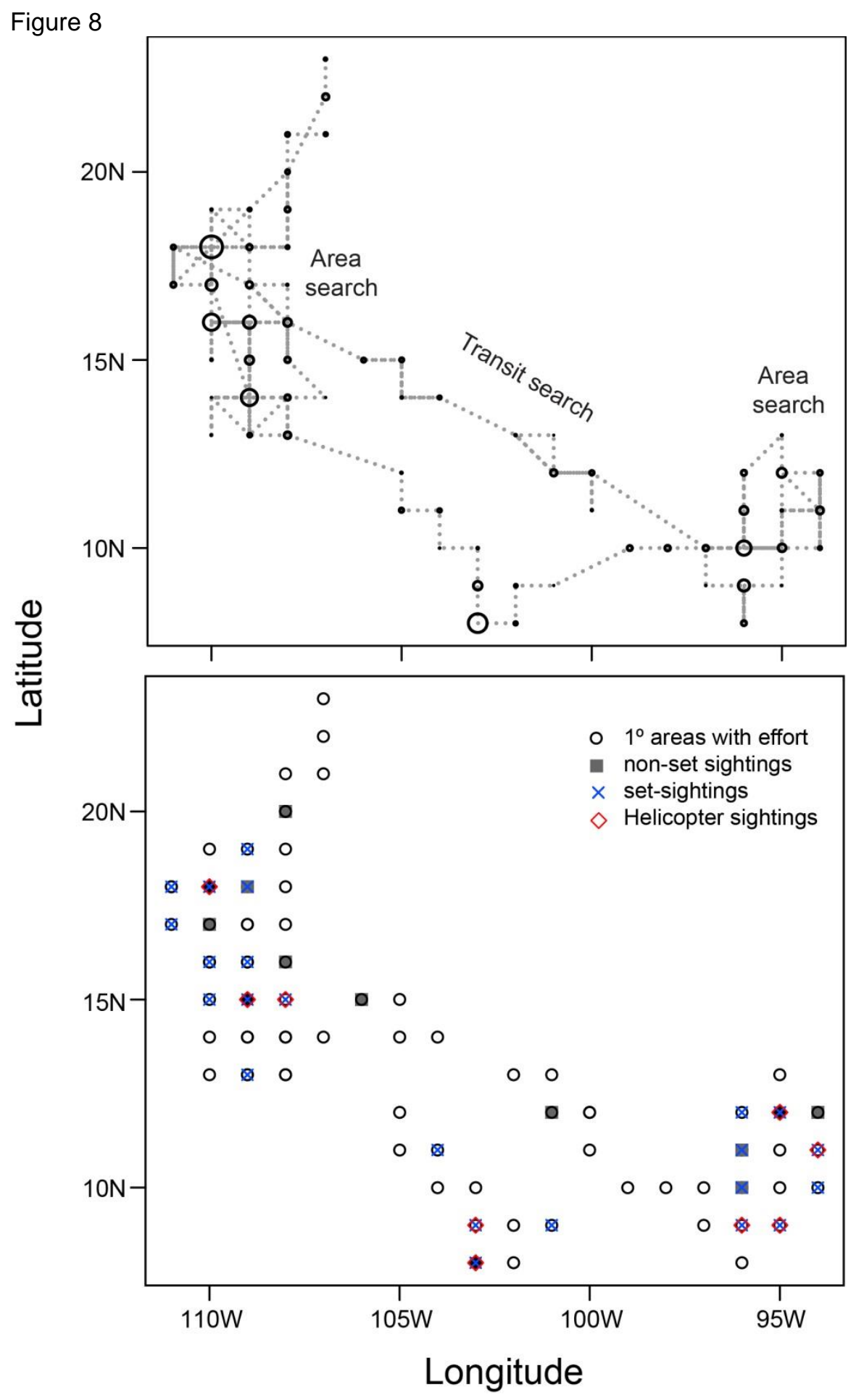




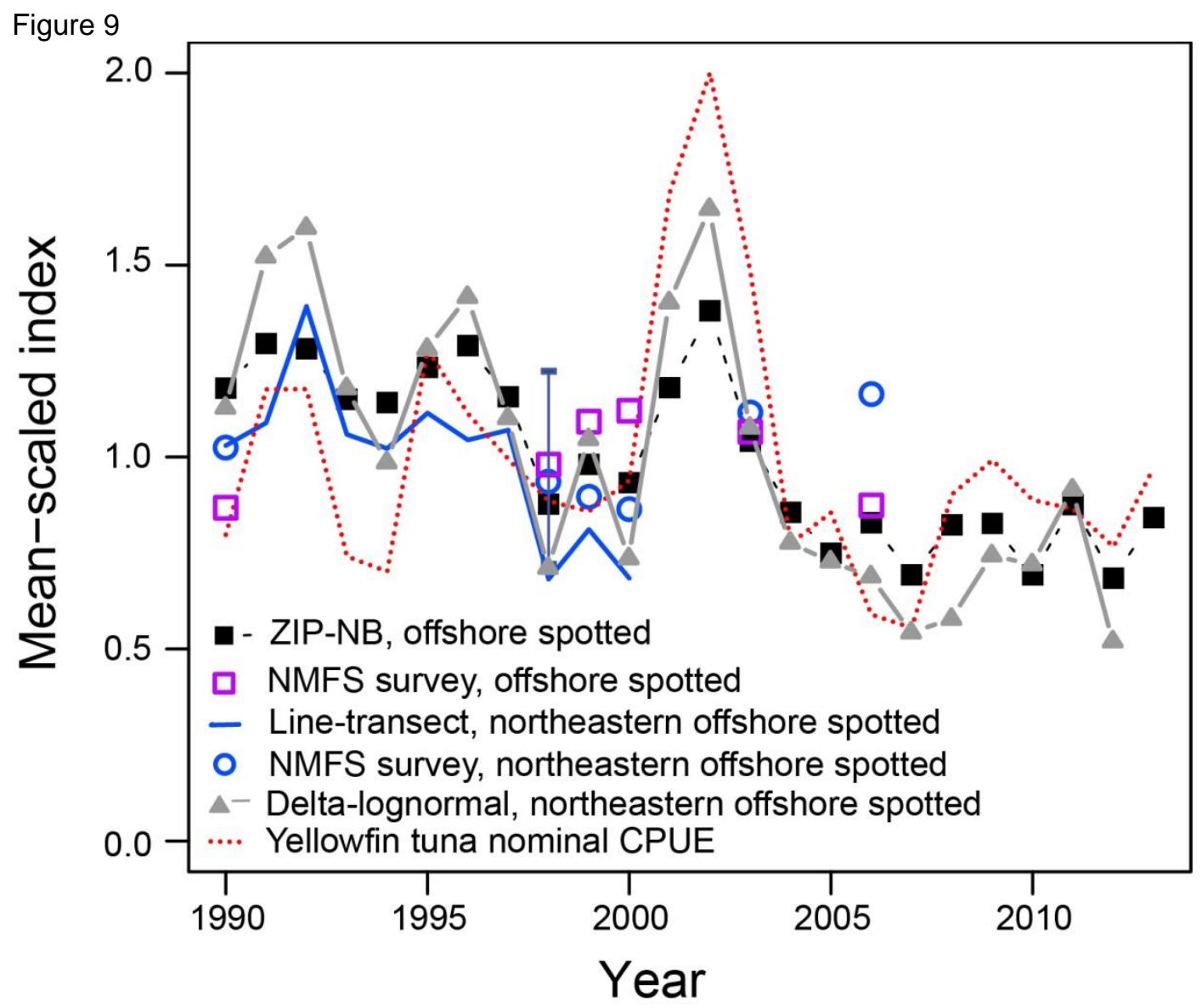

